\title{
COLABORAÇÃO EM TAREFAS DE INVESTIGAÇÃO: UM CAMINHO PARA O DESENVOLVIMENTO PROFISSIONAL DE PROFESSORES DE FÍSICA E QUÍMICA
}

\author{
COLLABORATION IN INQUIRY: A PATH FOR \\ THE PROFESSIONAL DEVELOPMENT \\ OF PHYSICS AND CHEMISTRY TEACHERS
}

\section{COLABORACIÓN EN TAREAS DE INVESTIGACIÓN: UN CAMINO HACIA EL DESARROLLO PROFESIONAL DE PROFESORES DE FÍSICA Y QUÍMICA}

\author{
Luísa Maria Geraldes Lourenço \\ Mónica Luísa Mendes Baptista ${ }^{\text {II }}$
}

\begin{abstract}
Resumo O desenvolvimento profissional de professores como fenômeno de mudança ao longo do tempo pode ocorrer num processo em que se cruza a dinâmica da mudança individual e coletiva, com vista a uma maior profissionalidade. Se a mudança constitui um processo, ela é, ao mesmo tempo, um produto, resultado de um processo de aprendizagem que inclui novas formas de pensar e de entender a prática quando confrontados com numerosos problemas, muitos dos quais de grande complexidade. Tratando-se de uma atividade profissional complexa, há toda a vantagem em recorrer aos esforços de uma equipe de trabalho em que os diversos professores trabalham em conjunto numa base de relativa igualdade, de modo a haver ajuda mútua para atingirem os mesmos objetivos. Este artigo descreve um estudo que visa compreender de que modo a colaboração potencia o desenvolvimento profissional de professores de Física e Química. Nesse quadro, criou-se um grupo colaborativo com um projeto de intervenção (PI) assente na concepção e realização de tarefas de investigação (TI) na sala de aula. Os dados foram recolhidos recorrendo a entrevistas, gravações-vídeo e notas de campo, tanto das sessões do PI, como das aulas de realização
\end{abstract}

IEscola Secundária Ibn Mucana, Alcabideche, Lisboa - Portugal.

"Instituto de Educação da Universidade de Lisboa, Lisboa - Portugal. 
das TI. Os resultados mostraram que a colaboração promoveu a realização de aprendizagens relacionadas com a natureza e concepção das TI e com a sua condução em aula.

Palavras-chave: Desenvolvimento profissional; Colaboração; Tarefas de investigação.

Abstract The professional development of teachers as a phenomenon of change over time can happen in a process that crosses a change of individual and collective change, with a view to greater professionalism. If a change is a process, it is at the same time a product, the result of a learning process that includes new ways of thinking and understanding the practice when faced with numerous problems, many of which are of great complexity. Being a complex professional activity, there is a whole advantage of using the efforts of a work team in which the various teachers work together on a basis of equality so that mutual help can be achieved to reach the same objectives. This article reports a study that aims to understand how the collaboration enhances the professional development of Physics and Chemistry teachers. In this context, we created a collaborative group with an intervention project (IP) based on the conception and implementation of inquiry in the classroom. Data were collected using interviews, video-recordings and log notes, both from the sessions of the IP and from the lessons of accomplishment of inquiry. The results showed that the collaborative work promoted the achievement of learning related to the nature and conception of inquiry and its conduct in the classroom.

Key-words: Professional development; Collaborative work; InQuiry.

Resumen El desarrollo profesional de profesores como fenómeno de cambio en el paso del tiempo puede ocurrir en el proceso en el cruce de una dinámica de cambio individual y colectiva, con vista a una mayor profesionalidad. Se un cambio en el proceso, en el tiempo, en el producto, en el resultado de un proceso de aprendizaje que incluye nuevas formas de pensar y de entender una práctica cuando confrontados con muchos problemas. Tratamiento-se de una actividad profesional compleja, con toda la ventaja en el uso de los esfuerzos de un equipo de trabajo en el que los diversos profesores trabajan en el conjunto en la base de la igualdad de la misma manera. Este artículo presenta un estudio que busca entender de qué forma la colaboración potencia el desarrollo profesional de los profesores de Física y Química. Así, hemos creado un grupo colaborativo con un proyecto de intervención (PI) basado en la concepción y realización de tareas de investigación (TI) en clase. Los datos fueron recolectados a través de entrevistas, vídeo grabaciones y registro de notas en sesiones del PI y en las clases de TI. Los resultados mostraron que la colaboración promueve el logro de los aprendizajes relacionadas con la naturaleza y concepción de las TI y con su dirección en clase.

Palabras claves: Desarrollo profesional; Colaboración; Tareas de investigación.

\section{INTRODUÇÃo}

O professor é a figura central nos processos de ensino e de aprendizagem de Ciências e o agente fundamental no desenvolvimento do seu conhecimento profissional. Para tal,

84 Comunicações |Piracicaba | v. 24 | $\mid$ n. 1 | | p. 83-98 |janeiro-abril 2017 
não basta, apenas, ele identificar o que tem de saber para o seu exercício profissional e quais as concepções que estruturam esse saber, mas também tem de perceber a natureza desse saber, indissociavelmente ligado à ação do professor, e o modo como é constituído, a partir da experiência e da reflexão sobre a experiência, não só individual, mas de uma equipe de professores que trabalham em conjunto para atingirem os mesmos objetivos.

$\mathrm{Na}$ verdade, a colaboração constitui uma estratégia para lidar com problemas comuns que se afiguram demasiado complexos para serem enfrentados em termos individuais. $\mathrm{O}$ trabalho colaborativo, a partir da discussão e partilha de ideias, tende a aumentar o grau de motivação dos professores, incentivando-os a um maior envolvimento na aproximação de novo conhecimento pedagógico-didático do conteúdo e na resolução de problemas (ROLDÃO, 2007). Daí a importância do trabalho colaborativo para os professores, tendo em conta que este permite a aquisição de novas aprendizagens e a resolução de problemas que se confrontam todos os dias (PENUEL et al., 2007).

A tomada de consciência de uma valorização do trabalho colaborativo como prioridade fundamental dos professores leva a reconhecer a necessidade destes partilharem as suas perspectivas, observações e experiências de modo a tomarem decisões em conjunto (SAAB, VAN JOOLINGEN, VAN HOUT-WOLTERS, 2012), que lhes permitam a resolução de problemas, rever e renovar os seus conhecimentos didáticos. Os professores, ao trabalharem colaborativamente, precisam de entender e de concordar com as contribuições dos seus pares, a fim de construir o conhecimento profissional adequado que os leve a refletir sobre a sua própria prática letiva (CHOUNTA e AVOURIS, 2014; SAAB, VAN JOOLINGEN, VAN HOUT-WOLTERS, 2012).

No entanto, o processo de crescimento, marcado por uma mudança das concepções dos professores não é fácil (AVALOS, 2001), pois a "inconsistência" entre algumas concepções dos professores e as respectivas práticas, que seguem rumos aparentemente incompatíveis, é deveras intrigante. Esse problema torna evidente a necessidade de alargar o quadro conceptual de análise sobre as ideias, os conhecimentos e o modo de pensar do professor. Para tal, é necessário identificar o que o professor tem de saber para o seu exercício profissional e quais as concepções que estruturam esse saber, bem como a natureza desse saber (PONTE, 2012).

Mas, o processo de mudança de concepções dos professores exige que estes, ao modificarem as suas práticas letivas tradicionais, tenham em conta o desenvolvimento de competências, de forma a permitir avanços no conhecimento e mudanças de práticas sustentadas de sala de aula (SCARDAMALIA e BEREITER, 2008; SONG e LOOI, 2011). As concepções dos professores sobre o ensino e a aprendizagem influenciam a forma como estes planificam e interpretam o currículo, bem como executam os seus planos de aula (KÖNINGS et al., 2014; SONG e LOOI, 2011). No caso das concepções dos professores acerca do ensino e da aprendizagem, resultados de vários estudos têm mostrado que a mudança de concepções dos professores e as mudanças das suas práticas, com vista ao desenvolvimento profissional, estão interligadas (JACOBSON et al., 2010; KIM et al., 2013; SONG e LOOI, 2011; TILLEMA e ORLAND-BARAK, 2006) e que o trabalho colabora- 
tivo pode levar os professores a aprender a respeito do tópico a lecionar e a desenvolver-se como profissionais (BOAVIDA e PONTE, 2002; LOTTER, RUSHTON, SINGER, 2013; RIGELMAN e RUBEN, 2012).

De fato, a literatura menciona que, quando os professores refletem em pequeno grupo sobre as concepções dos seus próprios colegas, promovem a aquisição de novas práticas (KIM et al., 2013; YOON e KIM, 2010). Ou seja, a colaboração facilita a troca de conhecimentos entre os professores a partir das suas experiências, permitindo que cada professor se conheça a si próprio e que se questione a si e aos outros (HIEBERT, GALLIMORE, STIGLER, 2002). O ato de refletir permite analisar as práticas, identificar os processos efetuados e reformular estratégias no sentido de resolver situações problemáticas. Assim, compreende-se que a colaboração seja capaz de promover novas práticas, dado que a alteração das mesmas requer o desenvolvimento de novas competências e uma mudança significativa das concepções dos professores.

Sendo assim, a colaboração potencia a reflexão efetiva ao longo de todo um processo e o desenvolvimento de competências de caráter social, processual e cognitivo dos seus intervenientes, de forma a promover um crescimento profissional dos professores.

Nesse quadro, torna-se pertinente colocar algumas questões sobre a interligação entre o envolvimento dos professores num trabalho colaborativo e o conhecimento profissional. Surge, assim, a problemática que configura o estudo apresentado: compreender de que modo o trabalho colaborativo potencia o desenvolvimento profissional de professores de Física e Química.

\section{CONTRIbUto da COlABoraÇão PARA O DESENVOLVIMENTO PROFISSIONAL}

A colaboração profissional dos professores é um conceito multifacetado, assumindo naturezas e formas diversas. Como denominador comum a todas elas está a interação entre profissionais procurando alcançar um objetivo geral ou, pelo menos, um interesse comum, partilhado por todos e objetivos individuais explícitos ou implícitos, conscientes ou inconscientes, de cada um dos professores da equipe (BOAVIDA e PONTE, 2002). Para Hargreaves (1998), a colaboração entre professores permite que realizem uma aprendizagem conjunta, uns com os outros, numa partilha de saberes e o ampliar do conjunto das suas competências, fomentando o desenvolvimento profissional dos mesmos.

A colaboração, ao contrário de outras formas de relacionamento entre pessoas (como seja a colegialidade), tem certo caráter de imprevisibilidade, dado que é um processo aberto, adaptativo e controlado internamente pelos participantes. A imprevisibilidade advém do fato de que toda a colaboração pressupõe negociações e tomada de decisões conjunta, partilha de informação, comunicação efetiva e aprendizagem mútua num empreendimento que se foca na promoção do diálogo profissional, onde os vários participantes, sem relação hierárquica, trabalham em conjunto para atingirem os mesmos objetivos e interesses comuns (DAY, 2001). Por meio da verbalização e interação, os professores formulam ideias, aprendem uns com os outros, interiorizam a teoria, criticam as suas concepções e as dos outros, 
aumentam os seus conhecimentos e discutem novas estratégias de ensino e aprendizagem (LOUCKS-HORSLEY et al., 1998). Desse modo a colaboração proporciona momentos de aprendizagem mútua e potencia reflexões individuais, o que pode ajudar a promover o desenvolvimento profissional dos professores envolvidos (HARGREAVES, 1998).

$\mathrm{Na}$ verdade, para o desenvolvimento profissional dos professores, a colaboração oferece importantes contribuições, que a tornam num valioso recurso. São várias as razões para que isso se verifique:

\footnotetext{
- Juntando diversas pessoas que se empenham num objetivo comum, reúnem-se, só por si, mais energias do que as que possui uma única pessoa, fortalecendo-se, assim, a determinação em agir.

- Juntando diversas pessoas com experiências, competências e perspectivas diversificadas, reúnem-se mais recursos para concretizar, com êxito, um dado trabalho, havendo, deste modo, um acréscimo de segurança para promover mudanças e iniciar inovações.

- Juntando diversas pessoas que interagem, dialogam e refletem em conjunto, criam-se sinergias que possibilitam uma capacidade de reflexão e um aumento das possibilidades de aprendizagem mútua, permitindo, assim, ir mais longe e criando melhores condições para enfrentar, com êxito, as incertezas e obstáculos que surgem (BOAVIDA e PONTE, 2002, p. 44-45).
}

Nos grupos em que se promove um trabalho entre professores, o insucesso e a incerteza não são protegidos e defendidos, mas sim protegidos e discutidos, tendo em vista ajudar e apoiar o desenvolvimento profissional do professor. Um dos efeitos da colaboração entre professores é o impacto na incerteza sentida relativamente ao trabalho, a qual, quando experienciada a sós, pode enfraquecer o sentimento de confiança. Daí que os professores que trabalham em colaboração conseguem mais facilmente proceder a levantamento e exploração de problemas ou dilemas identificados pelos próprios professores (PENUEL et al., 2007).

No quadro da realização de trabalhos colaborativos, em ligação direta com a prática letiva, Saraiva e Ponte (2003) evidenciam três fatores suscetíveis de promover o desenvolvimento profissional dos professores: (i) o enquadramento favorável à experimentação que se traduz pela existência e constituição de uma equipe de trabalho; (ii) o trabalho de equipe desenvolvido de forma reflexiva, segundo o ritmo, necessidades e interesses dos professores, no contexto natural do trabalho de escola, de forma a criar um sentimento de autoconfiança e de confiança mútua, partilha de receios e teorização da prática, e (iii) o desejo de inovar e fazer melhor.

\section{Metodologia}

Neste estudo participaram três professores, Ana, Rita e João, que lecionaram a disciplina de Física e Química aos alunos do $7^{\circ}$. ano de escolaridade, entre novembro de $2013 \mathrm{e}$ maio de 2014, e aos mesmos alunos que transitaram para o $8^{\circ}$. ano entre setembro de 2014 e fevereiro de 2015 numa escola situada na área da Grande Lisboa. 
O estudo incluiu um projeto de intervenção (PI) que visou promover o trabalho colaborativo entre os três professores de Física e Química na concepção e realização de tarefas de investigação (TI) na sala de aula e fomentar a reflexão sobre a prática. Para atingir essas finalidades, o projeto desenvolveu-se segundo três vertentes: (i) ensino por investigação; (ii) reflexão centrada na prática; e (iii) colaboração. Na primeira vertente do PI, o ensino por investigação, foi dada ênfase à seleção, adaptação e construção de TI baseadas no modelo instrucional fundamentado nos 5 E's ${ }^{1}$ (BYBEE et al., 2006), bem como à planificação de aulas. Na segunda vertente do projeto, a reflexão centrada na prática, é tido em conta a recolha de dados quando da realização das TI em sala de aula e a reflexão em grupo alicerçada nos dados recolhidos. E, por último, a terceira vertente do projeto, a Colaboração, foi valorizada ao longo das várias etapas do PI. A investigadora participou nas diversas fases do projeto, tendo conduzido as sessões de planeamento das aulas e construção das tarefas, observado as aulas dos professores envolvidos e participado na reflexão pós-aula.

Os dados foram recolhidos por meio de gravações-vídeo e notas de campo: das sessões colaborativas de planificação das tarefas de investigação (ST); das aulas de realização das tarefas de investigação (A); das sessões de reflexão colaborativas sobre a realização das tarefas de investigação em aula (ST); e de entrevistas semiestruturadas individuais aos professores no início da unidade didática "Materiais" ( $1^{\circ}$. Momento), após ensinar essa unidade ( $2^{\circ}$. Momento) e no final do desenvolvimento do PI ( $3^{\circ}$. Momento).

Quanto à análise dos dados recolhidos, a investigadora começou por transcrever e analisar os registros de todas as gravações-vídeo (sessões de trabalho colaborativo e entrevistas semiestruturadas), bem como, por analisar as notas de campo que descreviam as sessões de trabalho colaborativo, as aulas de realização das TI e as entrevistas semiestruturadas. Os dados foram lidos várias vezes de forma a descobrir padrões, singularidades e temas associados com a problemática. Identificaram-se assim a categoria, tarefa de investigação, e as subcategorias de codificação: (i) natureza das tarefas; (ii) concepção das tarefas; e (iii) condução das tarefas na sala de aula.

\section{Resultados}

O estudo realizado evidencia que os professores consideraram que o trabalho colaborativo levado a cabo com o PI promoveu a realização de aprendizagens relacionadas com a natureza das TI, a concepção das mesmas e a sua condução na sala de aula, contribuindo, inevitavelmente, para ampliar o seu conhecimento sobre a prática letiva e por conseguinte o seu desenvolvimento profissional.

\section{Natureza das Tarefas de InVestigaÇão}

O trabalho colaborativo desenvolvido entre os três professores, no âmbito do PI, a partir da discussão e partilha de ideias, permitiu a aquisição de novos conhecimentos, levando-

\footnotetext{
${ }^{1}$ Engage (motivar), Explore (explorar), Explain (explicar), Extend (desenvolver) e Evaluate (avaliar).
} 
-os a mudanças nas suas percepções relativamente às atividades de natureza investigativa - tarefas de investigação - no que concerne às linhas orientadoras dessas atividades, potencialidades das mesmas, bem como, aos alunos a que se destinam.

Desde o primeiro momento, os três professores consideraram as TI como uma atividade em que o aluno é confrontado com uma situação que lhe suscita um problema e que por meio da pesquisa ele sugere respostas para o problema em causa. Pela pesquisa o aluno envolvese de uma forma ativa na procura de evidências para encontrar uma ou mais respostas às questões colocadas. Por exemplo, Ana, nas entrevistas realizadas ao longo do PI, referiu:

\footnotetext{
Numa TI, os alunos testam as suas hipóteses não na prática - fazendo - mas sim no papel ( $1^{\circ}$. Momento).

As TI pressupõem que os alunos investiguem sobre determinados assuntos, formulem hipóteses, comprovem na prática as hipóteses levantadas, se for caso disso, recolham os dados, analisem os mesmos e concluam acerca das hipóteses levantadas ( $2^{\circ}$. Momento).

Uma TI, também, pressupõe a partilha de ideias, opiniões [...] entre os alunos de forma a construírem as suas próprias ideias sobre uma possível solução para um determinado problema ( $3^{\circ}$. Momento).
}

À medida que o trabalho colaborativo desenvolveu-se no âmbito do PI, os professores aperceberam-se que as TI não se baseavam unicamente na observação e na experimentação por parte dos próprios alunos, mas que as TI envolvem os alunos, de uma forma ativa na procura do caminho a seguir para encontrar uma ou mais soluções através do desenvolvimento de tarefas multifacetadas, tais como: (i) pesquisar sobre determinados assuntos; (ii) elaborar os seus próprios planos de investigação; (iii) executar os seus planos de investigação; (iv) analisar os seus dados; (v) comunicar os seus resultados; e (vi) concluir acerca das suas experiências relativas ao assunto a pesquisar.

Acresce-se, ainda, que no início do PI, dada a complexidade do processo de aprendizagem desenvolvido pelos próprios alunos, os professores revelaram apreensão quanto ao fato de as TI surtirem resultados positivos em todos os alunos e em todos os anos de escolaridade. Contudo, no final do desenvolvimento do PI, Rita quando questionada sobre a aplicabilidade das TI nos seus alunos mencionou que "a atitude dos alunos perante as TI foi ótima! Os alunos aprenderam imenso e estiveram sempre com prazer a resolver as $\mathrm{TI}$ " ( $3^{\circ}$. Momento).

Em outra vertente, é de realçar que durante a primeira fase do PI, os professores referiram que as TI colocaram os alunos no centro das suas aprendizagens, despertaram a curiosidade dos alunos no estudo de determinados assuntos, promoveram a compreensão de fenômenos - situações concretas do dia-a-dia - e suportaram o raciocínio e o pensamento crítico. Por sua vez, consideram que esse tipo de atividade tem uma série de propósitos no que concerne às aprendizagens realizadas pelos alunos, como sejam: (i) que saibam trabalhar em grupo; (ii) que saibam gerir o tempo; e que (iii) não tenham dificuldades na produção de textos escritos. 
À medida que se realizaram as TI em aula, sendo estas mais ou menos orientadas, os professores foram levados a afirmar que as TI são facilitadoras da construção do conhecimento e da compreensão dos fenômenos científicos. Por exemplo, João, nas entrevistas realizadas ao longo do PI referiu:

As TI levam os alunos a descobrir em vez de ser os professores a dizer tudo ( $1^{\circ}$. Momento).

As TI criam nos alunos hábitos de pensar e de pesquisar por eles próprios $\left(2^{\circ}\right.$. Momento).

Um aspecto fulcral das TI é que os alunos são incentivados a dar prioridade às evidências para responder às questões, a usar evidências para desenvolver explicações, ligando-as ao conhecimento científico e a comunicar as suas explicações. Essas caraterísticas levaram os professores a afirmar no final do desenvolvimento do PI que:

A realização das TI nas aulas de Química, mais ou menos orientadas na sua condução, promoveu a autonomia e o espírito crítico e científico nos alunos (Rita, $3^{\circ}$. Momento).

A realização das TI permite que os alunos ao partilharem as suas opiniões/ideias em grupo sejam capazes de se autocorrigirem ou de reforçarem a sua ideia/ opinião através do diálogo com os colegas - argumentando convenientemente (João, $3^{\circ}$. Momento).

Acresce-se, ainda, que as TI permitem ao professor perceber se o aluno compreendeu determinado tópico, bem como desenvolver competências de trabalho em grupo e de organização e gestão do tempo.

Assim, os professores no final do desenvolvimento do PI consideraram que as TI surtem resultados positivos em todos os alunos, desde que: (i) tenham boa propensão para o trabalho (Ana, $2^{\circ}$. Momento); (ii) sejam empenhados e persistentes (Ana, $2^{\circ}$. Momento); (iii) sejam curiosos (Rita, $5^{\mathrm{a}}$. ST); e (iv) tenham uma postura comportamental adequada em grupo (João, 12ª . ST).

\section{CONCEPÇÃO DAS TAREFAS DE INVESTIGAÇÃO}

O grau de abertura das TI foi um dos assuntos que mais promoveram a partilha e o confronto de ideias entre os professores do estudo. No início do desenvolvimento do PI, os professores manifestaram desconforto em relação à construção de tarefas abertas referindo que os alunos, perante uma tarefa cujo enunciado não diz especificamente o que deve fazer, não têm capacidade de decidir o que fazer e como o fazer. O diálogo que se segue explicita a discussão na $3^{\text {a. }}$. ST referente ao grau de abertura da primeira TI - Constituição do mundo real:

João - Como é que os alunos vão agrupar os materiais a partir da figura?

Ana - Temos que escrever na própria tarefa, a definição de materiais naturais e de materiais sintéticos! E depois colocamos uma tabela com o título - materiais 
naturais - e outra tabela com o título - materiais sintéticos - e pedimos aos alunos para distribuírem os materiais ilustrados na figura pelas respectivas tabelas. Rita - Os alunos só assim é que conseguem ver a diferença entre os dois grupos de materiais.

Contudo, após a realização das quatro primeiras TI na sala de aula e reflexão sobre as mesmas, o desconforto inicial parece ter sido gradualmente ultrapassado pelos professores através do trabalho colaborativo impulsionado pela investigadora, como se pode verificar por intermédio do diálogo na $9^{\mathrm{a}}$. ST referente à construção da $5^{\mathrm{a}}$. TI:

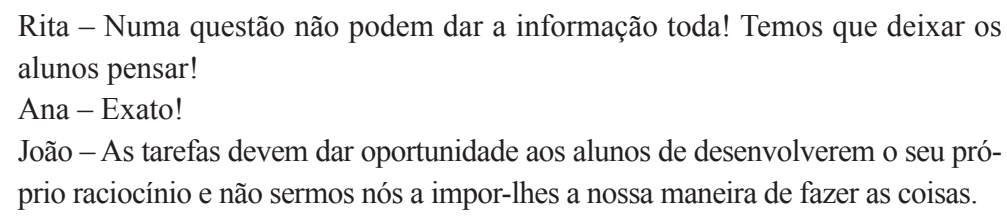

Assim, pode-se afirmar que o trabalho colaborativo desenvolvido no âmbito do PI fomentou a discussão sobre o grau de abertura das TI, levando os professores a superar gradualmente os seus receios, dado que constataram que as tarefas de natureza mais aberta favorecem o envolvimento dos alunos nas suas atividades encorajando-os a explorar e a investigar a respeito de um dado assunto.

Quanto à relevância de associar as TI a um contexto ou a uma situação do dia-a-dia foi outro assunto discutido em grupo e em várias sessões de construção das TI. Na $1^{\text {a }}$. fase do PI, os professores enfatizaram a necessidade de recorrer a objetos reais para complementar a situação problemática apresentada de inúmeras formas. Por exemplo, João, na $7^{\mathrm{a}}$. ST, referiu: "ter a imagem dos objetos na tarefa e em simultâneo colocar as respectivas imagens ao vivo num tabuleiro, na sala de aula, para os alunos poderem observar com pormenor". Segundo os professores envolvidos nesse estudo, os objetos reais apoiam a introdução de conceitos e também podem ser utilizados pelos alunos nas suas atividades ao longo da aula como meio de apoio, de exploração e de comunicação dos seus resultados. Em contrapartida, na $2^{\mathrm{a}}$. fase do PI, os professores referem que a situação problemática deve estar associada a um contexto ou a uma situação do dia-a-dia dia dos alunos, mas, também, deve ser determinante para o professor se aperceber do que os alunos já sabem e simultaneamente identificar concepções alternativas. Por exemplo, João, na 19". ST, referiu: "O fogo-de-artificio permitiu-me perceber quais os conhecimentos que os meus alunos tinham sobre o fogo-de-artificio e em simultâneo introduzir o conceito de reações de combustão".

O modo de estruturação das TI que engloba cinco etapas a desenvolver pelos alunos foi outro aspecto discutido e refletido em colaboração nas várias sessões de construção e de reflexão sobre a realização das TI em aula. Ao longo do desenvolvimento de todo o PI, as interações entre os professores parecem ter sido construtivas e produtivas levando a sequenciar as atividades que os alunos iriam realizar ao longo das TI, levando os alunos a elaborar os seus próprios planos, testá-los, analisar e comunicar os resultados e avaliar e modificar as suas experiências. 
Em suma, os professores no início do PI revelaram, essencialmente, dificuldades ao nível da elaboração das questões que visassem o envolvimento do próprio aluno no seu processo de aprendizagem. Acresce-se, ainda, na $2^{\mathrm{a}}$. fase do desenvolvimento do PI, as dificuldades evidenciadas pelos professores ao nível da elaboração do engage, isto é, que envolvesse os alunos no estudo de determinado tópico, e na formulação de questões que levassem os alunos a explorar, explicar e a desenvolver as concepções que possuíam face ao tópico referenciado no engage.

\section{CONDUÇÃo das TAREFAS de INVESTIGAÇão}

Durante a realização das TI em sala de aula, o papel do professor, o processo de aprendizagem dos alunos, bem como a gestão e a organização da sala de aula foram alvo de discussão e de reflexão em grupo.

Quando da realização das primeiras TI, os professores sentiram-se inseguros em adotar o papel de facilitador da aprendizagem dos alunos, evidenciando constrangimentos em direcionar o trabalho dos alunos para que aprendessem por si próprios sem lhes transmitir explicitamente os saberes. Por exemplo, Rita, na $12^{\text {a }}$. ST, referiu:

Quando um grupo de alunos bloqueia numa questão de uma TI, eu tenho dificuldade em lhes lançar "dicas", através de questões que os coloquem a pensar de forma a desbloquearem e a conseguirem atingir o que se pretende com a questão.

Essas dificuldades não puderam ser evitadas, mas ao contrário, tiveram de ser enfrentadas e foram diminuindo à medida que as TI se realizaram. As sessões de trabalho colaborativo acerca de possíveis dificuldades apresentadas pelos alunos foram fundamentais como meio de levar os professores a adquirirem uma maior confiança. Por exemplo, Ana, na $2^{\mathrm{a}}$. entrevista, referiu:

Eu na realização das primeiras TI, em sala de aula, senti-me insegura pois não sabia o que podia dizer aos alunos sem lhes dar a resposta na sua totalidade. Mas, ao ver-te (a investigadora) atuar na aula perante as questões que os alunos te colocavam e através da reflexão em grupo sobre as possíveis dificuldades que os alunos irão manifestar na realização das TI em aula, bem como as possíveis estratégias de atuação face a estas dificuldades, deume cada vez mais confiança.

Por sua vez, à medida que o PI se desenvolveu, os professores foram potenciando nos alunos a aquisição e o desenvolvimento de competências: (i) atitudinais - saber trabalhar em grupo, em que cada elemento tem funções bem definidas; (ii) de comunicação - produção oral em pequeno grupo e à turma, e produção escrita; (iii) de conhecimento de processos - planificação de atividades e construção de tabelas; e (iv) de raciocínio - autocorreção. Por exemplo, Rita, na $2^{\mathrm{a}}$. entrevista, mencionou: 
As TI dão aos alunos competências de trabalho em grupo, de saber ouvir, de saber concluir, de saber ler vários tipos/formas de apresentação de conteúdos, de saber comunicar oralmente para um grupo alargado de pessoas, e de pensar por si próprios.

De fato a partilha de ideias e as discussões em colaboração levaram os professores a promover um papel mais ativo dos alunos na sala de aula e os receios em realizar as TI em sala de aula foram diminuindo ao longo do desenvolvimento do PI.

$\mathrm{Na}$ realização das primeiras TI, em aula, os professores estavam reticentes em relação à qualidade das aprendizagens adquiridas pelos alunos. Por exemplo, João, na $7^{\mathrm{a}}$. ST, mencionou:

Eu tenho dúvidas que os alunos estejam a aprender com as tarefas de investigação [...] eu tenho dúvidas que as TI sejam produtivas para os alunos. Mas vamos fazendo!

Contudo, os professores reconheceram que as dúvidas quanto à qualidade das aprendizagens dos alunos foram diminuindo à medida que se realizaram mais TI, tendo a colaboração dado um contributo fundamental. Por exemplo, João que foi o mais reticente no que se refere à qualidade das aprendizagens dos alunos na entrevista realizada no final do desenvolvimento do PI referiu:

Para os próximos anos sempre que tiver oportunidade vou realizar TI em sala de aula pois os alunos aprendem, efetivamente, com este tipo de tarefas e eu também aprendo!

Tal mudança foi notória a partir da $2^{\mathrm{a}}$. metade do desenvolvimento do PI e teve implicações ao nível do papel que os professores atribuem a si mesmos no que se refere ao desenvolvimento da própria aula - plano de aula - à planificação a curto prazo e ao diagnóstico das dificuldades reveladas pelos alunos na realização das TI. De fato, a colaboração permitiu que a concepção que os professores tinham a respeito do que é o saber, em que contexto e a forma onde e como ele é adquirido passassem a ser encarados segundo outra perspectiva. Por sua vez, os professores estavam cientes que ao realizarem as TI em aula iriam quebrar as suas rotinas e a dos alunos. Daí que, na realização das primeiras TI, os professores mostrassem receios sobre o funcionamento dos alunos em grupo - "andava constantemente de grupo em grupo a supervisionar as respostas dadas pelos alunos" (Rita, $4^{\mathrm{a}}$. ST) - e preocupados em relação à organização da sala - "previamente organizei as salas em grupo" (Ana; $1^{\mathrm{a}}$. e $2^{\mathrm{a}}$. A) - e à duração das TI - "no inicio da aula estipulou-se no quadro e/ou oralmente o tempo máximo destinado a cada questão das TI" (Rita, $2^{\circ}$. Momento; João, $2^{\circ}$. Momento).

No decorrer do PI, todos os receios foram sendo ultrapassados por meio do apoio transmitido pelo grupo de trabalho colaborativo, permitindo que os professores realizassem aprendizagens relativas ao modo de gerir uma sala de aula durante a realização de TI. 


\section{CONSIDERAÇões FINAIS}

O desenvolvimento profissional dos professores, no contexto do projeto de intervenção, assentou no progresso em três dimensões (o ensino por investigação, a reflexão centrada na prática e a colaboração) que permitiram um exercício da profissão com maior eficácia na resolução de problemas práticos e na adequação das soluções aos recursos existentes. De fato, a dinâmica reflexiva estabelecida no grupo de trabalho colaborativo, onde os comentários, a apresentação das ideias e as sugestões foram acompanhados com argumentos justificativos, permitiu aos professores a vivência de experiências positivas, indo ao encontro das necessidades de cada um dos professores e promovendo o seu desenvolvimento profissional. Assim, o PI parece ter constituído um contexto adequado e desafiante para os professores desenvolverem de forma gradual e progressiva, as suas capacidades de colaborar profissionalmente. As sessões de trabalho colaborativo do PI assentaram no respeito mútuo, confiança, confronto de ideias e chegada a consenso, quando da construção e realização das TI em sala de aula. O clima de confiança criado de forma gradual e progressiva ao longo do PI permitiu que os professores partilhassem os seus receios, e a reflexão sobre estes possibilitou-lhes não só superar os obstáculos que se depararam, como também, conduzi-los a novas experiências e à aquisição de novas aprendizagens.

Algumas das aprendizagens relacionaram-se com a natureza das TI, nomeadamente as suas linhas orientadoras, potencialidades e alunos a quem se destinam. Atendendo às necessidades de cada professor, trabalhou-se, de um modo geral, as TI do desenvolvimento de atividades multifacetadas que visam o envolvimento de todos os alunos de uma forma ativa na procura de caminhos a seguir para encontrar uma ou mais soluções, tais como: (i) pesquisar sobre determinados assuntos; (ii) elaborar os seus próprios planos de investigação; (iii) executar os seus planos de investigação; (iv) analisar os seus dados; (v) comunicar os seus resultados; e (vi) concluir a respeito das suas experiências relativas ao assunto a pesquisar.

Os professores no final do desenvolvimento do PI reconheceram que conseguiram ultrapassar o dilema natureza das TI versus natureza de outras formas de tarefas, contribuindo o trabalho colaborativo para se centrarem mais nas TI segundo o modelo instrucional dos 5 E's, dado que estas colocam os alunos no centro das suas aprendizagens, promovem a compreensão dos fenômenos, suportam a argumentação e a comunicação, bem como, o raciocínio e o pensamento crítico (LEDERMAN, 2010). Além disso, as reflexões sobre a realização das TI, na sala de aula, permitiram que os professores alterassem as suas ideias em relação aos alunos a que se destinam as TI. Este estudo mostrou que as TI surtem efeitos positivos em todos os alunos, desde que: (i) tenham boa propensão para o trabalho; (ii) sejam empenhados e persistentes; (iii) sejam curiosos; e (iv) tenham uma postura comportamental adequada em trabalho de grupo.

Outras aprendizagens estiveram relacionadas com a concepção das TI. À medida que os professores planificavam e construíam as TI, a estruturação segundo o modelo instrucional dos 5 E's, a abertura e os contextos e aplicações destas foram sendo discutidos. Os professores ao longo do desenvolvimento do PI foram tendo a noção que a estruturação das 
TI segundo o modelo instrucional dos 5 E's é uma estratégia de ensino que lhes permite envolver ativamente os alunos na sua própria aprendizagem de Ciências em sala de aula (BLONDER et al., 2014). Contudo, os professores, ao construírem as TI segundo os 5 E's, foram tendo a noção que quanto mais abertas são as tarefas, tanto mais estimulantes se tornam para os alunos, uma vez que lhes permitem desenvolver mais competências e dão maior margem para eles fazerem as suas opções. Além disso, as discussões sobre os contextos e aplicações das TI constituíram uma tarefa partilhada que os encorajou a enfrentar os dilemas que se depararam. A maioria dos professores no final do desenvolvimento do PI reconheceu que conseguiu envolver os próprios alunos no seu processo de aprendizagem e que conseguiu ultrapassar o dilema do grau de abertura das tarefas, contribuindo o trabalho colaborativo para centrar-se na construção de tarefas abertas.

Os professores realizaram ainda aprendizagens relacionadas com a condução das TI na sala de aula, evidenciando-se o papel do professor, a gestão e organização da sala de aula, bem como, o processo de aprendizagem dos alunos. À medida que os professores foram realizando as TI, em sala de aula, o papel do professor foi sendo discutido. Os professores foram tendo a noção que, ao assumirem um papel de facilitador da aprendizagem e não de transmissor de conceitos, fatos ou técnicas, os alunos aprendem mais e desenvolvem as suas próprias ideias. O professor deve ter em conta os modos próprios de aprender, de pensar e de fazer Química que os alunos desenvolvem ao longo da sua escolarização. Acresce-se que as discussões sobre a qualidade das aprendizagens adquiridas pelos alunos constituíram uma tarefa partilhada que os encorajou a enfrentar as dúvidas que se depararam. Os professores, nessa subcategoria, realizaram ainda aprendizagens a respeito da gestão e organização da sala de aula. Os professores no final do desenvolvimento do PI reconheceram que os receios face ao papel do professor, à qualidade das aprendizagens adquiridas pelos alunos e à gestão e organização da sala de aula foram sendo ultrapassados através do apoio transmitido pelo grupo de trabalho colaborativo.

É nesse quadro que se pretende compreender de que modo o trabalho colaborativo potencia o desenvolvimento profissional de professores de Física e Química. No caso do trabalho colaborativo desenvolvido entre os três professores que integraram o PI, verificou-se que, por meio da verbalização e interação, os professores formularam ideias, aprenderam uns com os outros, interiorizaram a teoria, criticaram as suas concepções e as dos outros, aumentaram os seus conhecimentos e discutiram novas estratégias de ensino e aprendizagem. Dessa forma, a colaboração proporcionou momentos de aprendizagem mútua e potenciou reflexões individuais promovendo o desenvolvimento profissional dos professores envolvidos. 


\section{REFERÊNCIAS}

AVALOS, B. Teacher professional development in teaching and teacher education over ten years. Teaching and Teacher Education, EUA, v. 27, p. 10-20, 2001.

BLONDER, RON; et al. Questioning behavior of students in the inquiry chemistry laboratory: differences between sectors and genders in the Israeli context. International Journal of Science and Mathematics Education. Dordrecht, Holanda, p. 1.305-1.331, 2014.

BOAVIDA, A. M.; PONTE, J. P. Investigação colaborativa: Potencialidades e problemas. In: GTI (Org.). Reflectir e investigar sobre a prática profissional, Lisboa: APM, 2002, p. 43-45.

BYBEE, R. W.; et al. The BSCS 5E instructional model: origins, effectiveness, and applications, USA: Colorado Springs, 2006.

CHOUNTA, I.; AVOURIS, N. Toward the real-time evaluation of collaborative activities: Integration of an automatic rater of collaboration quality in the classroom from the teacher's perspective. Education and Information Tecnologies, New York, 2014. Disponível em: <http: //DOI10.1007/s10639-014-9355-3> Acesso em: 5 de jan., 2016.

DAY, C. Desenvolvimento profissional de professores: os desafios da aprendizagem permanente, Porto: Porto Editora, 2001.

HARGREAVES, A. Os professores em tempo de mudança: $O$ trabalho e a cultura dos professores na idade pós moderna, Lisboa: Mc Graw-Hill, 1998.

HIEBERT, J.; GALLIMORE, R.; STIGLER, J. A knowledge base for the teaching profession: What would it look like and how can we get one? Educational Researcher, EUA, v. 31, n. 5, p. 3-15, 2002.

JACOBSON, M. J. et al. Epistemology and learning: Impact on pedagogical practices and technology use Singapore schools. Computers \& Education, Singapora, v. 55, n. 4, p. 1.694-1.706, 2010.

KIM, M.; et al. Teacher's reflection of inquiry teaching in Finland before and during an in-service program: examination by a progress model of collaborative reflection. International Journal of Science and Mathematics Education, Dordrecht, Holanda, v. 11, p. 359-389, 2013.

KÖNINGS, K. D. et al. Differences between students' and teachers' perceptions of education: profiles to describe congruence and friction. Instructional Science, Dordrecht, Holanda, v. 42, 2014. Disponível em: <http://DOI10.1007/s11251-013-9294-1> Acesso em: 5 de jan., 2016.

LEDERMAN, L. Understanding corporate taxation, 2. ed., Newark: LexisNexis, 2010. 
LOTTER, C.; RUSHTON, G. T.; SINGER, J. Teacher enactment patterns: How can we help move all teachers to reform-based inquiry practice through professional development? Journal of Science Teacher Education, EUA, v. 24, 2013. Disponível em: < http:// DOI10.1007/s10972-013-9361-0> Acesso em: 5 de jan., 2016.

LOUCKS-HORSLEY, S.; et al. Designing professional development for teachers of science and mathematics, Thousand: Corwin Press, 1998.

PENUEL, W. R.; et al. What makes professional development effective? Strategies that foster curriculum implementation. American Educational Research Journal, EUA, v. 44, n. 4, p. 921-958, 2007.

PONTE, J. P. Estudando o conhecimento e o desenvolvimento profissional do professor de matemática. In: N. Planas (Org.). Educación matematics: Teoria, critica y prática, Barcelona: Graó, 2012.

RIGELMAN, N.; RUBEN, B. Creating foundations for collaboration in schools: Utilizing professional learning communities to support teacher candidate learning and visions of teaching. Teaching and Teacher Education, EUA, v. 28, n. 7, p. 979-989, 2012.

ROLDÃO, M. C. A função curricular da escola e o papel dos professores: políticas, discursos e práticas de contextualização e diferenciação curricular. Nuances: Estudos sobre Educação, São Paulo, v. 7, n.18, p. 230-241, 2007.

SAAB, N.; VAN JOOLINGEN, W.; VAN HOUT-WOLTERS, B. Support of the collaborative inquiry learning process: influence of support on task and team regulation. Metacognition Learning, Springerlink.com, v. 7, n. 7, 2012. Disponível em: <http://DOI10.1007/ s11409-011-9068-6> Acesso em: 5 de jan., 2016.

SARAIVA, M.; PONTE, J. P. O trabalho colaborativo e o desenvolvimento profissional do professor de Matemática. Quadrante, Lisboa, v. 12, n. 2, p. 25-52, 2003.

SCARDAMALIA, M.; BEREITER, C. Pedagogical biases in educational technologies. Educational technology Magazine: NJ, v. 48, n. 3, p. 3-11, 2008.

SONG, Y.; LOOI, C. Linking teacher beliefs, practices and student inquiry-based learning in a CSCL environment: A tale of two teachers. Computer-Supported Collaborative Learning, LLC, v. 17, 2011. Disponível em: <http://DOI:10.1007/s11412-011-9133-9> Acesso em: 5 de jan., 2016.

TILLEMA, H.; ORLAND-BARAK, L. Constructing knowledge in professional conversations: The role of beliefs on knowledge and knowing. Learning and Instruction, UK, v. 16, n. 6, p. 592-608, 2006.

YOON, H.; KIM, M. Collaborative reflection through dilemma cases of science practical work during practicum. International Journal of Science Education, Singapora, v. 32, n. 3, p. 283-301, 2010. 


\section{Dados das Autoras}

Luísa Maria Geraldes Lourenço

Escola Secundária Ibn Mucana, Alcabideche, Lisboa - Portugal. luisamgl@hotmail.com

Mónica Luísa Mendes Baptista

Instituto de Educação da Universidade de Lisboa, Lisboa - Portugal. mbaptista@ ie.ulisboa.pt

Submetido em: 28-12-2016

Aceito em: 2-3-2017 